\title{
O DITO E NÃO DITO ACERCA DAS RELAÇÕES DE GÊNERO NO COTIDIANO DAS AULAS DE MATEMÁTICA ${ }^{1}$
}

Lindamir Salete Casagrande lindasc@utfpr.edu.br

Universidade Tecnológica Federal do Paraná (UTFPR), Curitiba, Paraná, Brasil.

Marilia Gomes de Carvalho mariliagdecarvalho@gmail.com Universidade Tecnológica Federal do Paraná (UTFPR), Curitiba,

Paraná, Brasil

\section{RESUMO}

O objetivo deste artigo é apresentar uma parcela dos resultados da pesquisa para realização da tese de doutorado cujo objetivo foi analisar as relações de gênero no cotidiano das aulas de matemática de 5 a a $8^{a}$ séries do ensino fundamental. A pesquisa foi realizada em um colégio da rede estadual de ensino de Curitiba, capital do Estado do Paraná, Brasil. A pesquisa foi baseada no método etnográfico com observação, entrevista e análise de documentos. A análise foi feita com base na teoria de gênero buscando identificar o dito e não dito acerca das relações de gênero presentes naquele espaço. Os resultados apontam um silenciamento das relações de gênero e das alunas. Elas parecem ter absorvido a ideia de que devem ouvir mais do que falar, de que não devem se expor. Apontam ainda a necessidade que alunos e alunas tem de serem reconhecidos/as como pertencentes ao grupo. Essa necessidade contribuía para seu silenciamento. Professores/as e alunos/as percebiam as meninas como passivas e organizadas e os meninos como ativos e criativos. De modo geral, as percepções eram baseadas em estereótipos do que é ser homem ou mulher na sociedade atual, fato que demonstra que desde muito cedo estes estereótipos são absorvidos por meninas e meninos e passam a fazer parte de suas formas de pensar e ver as relações cotidianas.

PALAVRAS-CHAVE: Relações de Gênero. Aulas de Matemática. Alunos e alunas. 


\section{INTRODUÇÃO}

Este artigo tem como objetivo contribuir para a discussão da temática de gênero e educação no meio acadêmico. A pesquisa que deu origem a este artigo foi realizada durante o período de 2008 a 2011 para a realização de uma tese de doutorado ${ }^{2}$ desenvolvida junto ao Programa de pós-Graduação em Tecnologia PPGTE da Universidade Tecnológica Federal do Paraná - UTFPR. A tese foi defendida em dezembro de 2011 junto àquele programa.

Para o desenvolvimento da pesquisa foi utilizado o método etnográfico que prevê vários métodos de coleta de dados. Neste caso, utilizei a entrevista, a observação e a análise de documentos. Os resultados aqui apresentados são oriundos da triangulação dos dados obtidos por meio das três formas de coleta/produção de dados.

Foram pesquisadas quatro turmas do ensino fundamental, 5a a $8^{a}$ séries $^{3}$ de um colégio da rede estadual de ensino de Curitiba, capital do Estado do Paraná. 0 colégio localiza-se na região central da cidade e foi escolhido por ser um dos sete primeiros colégios de Curitiba e por ter tradição em ofertar ensino de boa qualidade. As turmas foram escolhidas de acordo com o horário das aulas para que eu pudesse assistir o máximo possível de aulas de Matemática em cada turma. Fiz observação por seis meses das aulas de Matemática das turmas escolhidas. Ao final das observações foram selecionados/as quarenta estudantes (vinte de cada sexo e dez de cada turma) para a entrevista. Convidei os/as estudantes e eles e elas tinham a opção de não aceitar, entretanto todos/as aceitaram e se mostraram felizes com a escolha. Entrevistei ainda os/as professores/as de Matemática (dois homens e duas mulheres) das referidas turmas e fiz a análise de documentos que continham as notas dos/as alunos/as.

A possibilidade de se conhecer um pouco mais esta temática me levou a pesquisar as aulas de Matemática. Outro fator a influenciar foi a minha formação em Licenciatura em Matemática que me desperta interesse em estudar esta disciplina. Os resultados deixam-me feliz e preocupada ao mesmo tempo. Feliz por apresentar um trabalho que pode contribuir com a reflexão sobre a temática e preocupada por perceber que ainda ocorrem situações de discriminação e silenciamento de uma parcela significativa da população escolar (as meninas) no meio educacional brasileiro.

Para a realização desta pesquisa parti do pressuposto de que o gênero é uma das categorias importantes nos estudos sobre a sociedade. A categoria gênero pode ser entendida "como uma linguagem, uma forma de comunicação e ordenação do mundo, que orienta a conduta das pessoas em suas relações específicas, e que é, muitas vezes, base para preconceitos, discriminação e exclusão social" (SIMIÃO, 2005: p. 13). Para Felipe e Guizzo (2003: p. 121), gênero está "relacionado fundamentalmente aos significados que são atribuídos ao ser mulher ou ao ser homem em diferentes sociedades e épocas". Já Scott (1995) considera que as relações de gênero são também relações de poder.

Para este artigo, parto do pressuposto de que o gênero é social e culturalmente construído. Representa e estabelece relação de poder entre os sujeitos de cada gênero e mesmo entre sujeitos do mesmo gênero (SCOTT, 1995; 
COSTA, 1994). Assim, todos os segmentos da sociedade contribuem para esta construção, inclusive a escola e os sujeitos que nela atuam.

Com relação à escola, parto do pressuposto de que ela não atua somente como mantenedora da cultura dominante e das regras estabelecidas pela sociedade. Pode ser um instrumento importante na transformação de tais normas para assegurar a todos/as o direito à educação. Desta forma, tem papel importante na construção das identidades de gênero dos/as estudantes, porém não é a única instituição responsável por esta construção. Outras instituições como família e igreja, além da mídia e do convívio em sociedade contribuem de forma significativa para tal construção. Como a pesquisa aqui apresentada foi realizada na escola, o artigo versará sobre o papel da escola nesta construção, porém sempre tendo em mente as demais instâncias que constituem os sujeitos.

Com este olhar adentrei a sala de aula e observei o que ocorria lá. Fui bem aceita pela maioria das turmas. A exceção foi a 7a série na qual, inicialmente as meninas me hostilizaram, porém após uns 15 dias a situação mudou e a aceitação ocorreu. Uma parcela dos resultados trago neste artigo.

\section{ADENTRANDO A SALA DE AULA}

Cheguei ao colégio centenário ${ }^{4}$ no mês de abril de 2009 e fui apresentada aos professores e professoras de matemática. Eram quatro profissionais (dois homens e duas mulheres) As mulheres lecionavam para a 5a e 6a série e os professores para a 7ạ e 8a série. Quando recebi esta informação pensei que era uma escolha deles em trabalhar com estudantes mais velhos mas logo tive esta dúvida esclarecida. Inicialmente eram quatro professoras e duas delas entraram em licença e por isso dois professores assumiram suas turmas. Não havia nenhuma questão de escolha ou preferência.

Durante as observações pude notar que as relações entre os alunos e alunas eram múltiplas. Havia relação de amizade, de companheirismo, de cooperação, de agressividade, de isolamento, dentre outras. Fui ali para observar as relações de gênero entretanto as questões de raça/etnia, classe, geração, religião, sexualidade também se faziam notar. Como não eram objeto de minha pesquisa, deixei a margem, porém com ciência de que elas estavam ali e influenciavam na forma como meninos e meninas se relacionavam.

Pude perceber que os/as estudantes preferiam se relacionar com colegas do mesmo sexo. Na 5a e 6a série praticamente não existia relação entre estudantes de sexos opostos. Na 7ạ e $8 \underline{a}$ série isso já ocorria com maior frequência, porém ainda era a minoria. Três estudantes chamavam a atenção por se relacionar preferencialmente com estudantes do sexo oposto. Eles/as eram Isabela da 7ạ série, Eliane e Pedro da $8^{a}$ série. Estes três estudantes também se destacavam pelo seu excelente rendimento escolar. Eliane e Pedro eram os discentes mais participativos e assertivos da turma. Isabela era mais calada mas também assertiva nos raros momentos em que se manifestava.

Os/as estudantes afirmaram em suas entrevistas que preferiam se relacionar com estudantes do mesmo sexo pois os assuntos eram semelhantes e ficava mais fácil de fazer amizade. As interações entre os/as colegas se davam para fins de lazer. Raramente percebi a troca de conhecimento entre eles e elas. Sabe-se que 
o conteúdo de Matemática se apresenta para muitos como complexo e de difícil assimilação e a troca mútua de conhecimento entre colegas que utilizam linguagem semelhante pode facilitar o aprendizado. Entretanto só observei este comportamento entre estudantes da 7ạ e 8a séries. Na 7ạ serie Fernanda era o ponto de referência. Muitas alunas se dirigiam a ela para sanar as dúvidas. Observem que eram só alunas que buscavam ajuda da colega. Na 8 a série a troca ocorria com mais frequência entre Eliane e Pedro Almeida. Pude perceber que havia o desperdício da oportunidade de conhecer e interagir com colegas de sexos diferentes e com isso se desperdiçava a oportunidade de crescimento mútuo que tal interação pode proporcionar.

Algumas meninas manifestaram a preocupação com a opinião dos/as outros/as, com o que os/as outros/as iam pensar se elas fossem a casa de um colega do sexo masculino para a realização de trabalhos escolares. Foi o caso de Bianca, aluna da 5a série que tinha preocupação em manter sua reputação ilibada. Se alguém questionasse o comportamento de algum dos dois estudantes que se reuniram para estudar, seria o dela e não o dele a ser questionado. Ela não podia se expor, tinha que se cuidar, ele não. Isso ficou evidente na fala de Bianca.

Em sala de aula, os meninos falavam alto, se deslocavam pela sala, confrontavam os/as professores/as e as meninas falavam baixinho, enviavam bilhetes ou se deslocavam discretamente e ao chegar a carteira da colega se agachavam com o intuito de que o professor ou professora não percebesse este fato. Este comportamento foi mais evidente entre estudantes da 6a série. Meninas e meninos usavam estratégias diferentes em sala de aula porém todos e todas obtinham êxito em suas intenções, a relação com os/as colegas ocorria.

O fato delas falarem baixinho dificultou o meu trabalho pois eu também não conseguia ouvir o que elas falavam e assim não tinha como saber quais eram os assuntos abordados por elas. No caso deles, os assuntos predominantes eram futebol, computadores, games e no caso da $8^{a}$ série, meninas. Devido a este comportamento diferenciado de meninas e meninos não pude saber se os assuntos eram realmente diferentes ou se esta era uma impressão equivocada por parte dos estudantes, embora o argumento deles/as era consistente ao afirmar esta diferença. Este comportamento diferenciado de meninas e meninos me levou a questionar os motivos pelos quais isso ocorre. Por que as meninas falavam baixinho e os meninos em voz alta? Ao que tudo indica, elas já haviam sido silenciadas pelo processo de socialização pelo qual passaram para chegar até ali.

Quando me apresentei aos/às estudantes disse que as minhas anotações estariam a disposição de alunos/as e professores/as e que eles e elas poderiam ver quando quisessem, porém apenas uma aluna me perguntou uma vez o que eu tanto escrevia e eu pedi se ela queria ver. Ela não quis. Nenhum/a professor/a teve curiosidade em conhecer meu diário de campo - DC.

O relacionamento dos/as estudantes com os/as professores/as era intenso. A Professora Marina que lecionava para a $5 \underline{a}$ série percebia diferença na postura de meninos e meninas. Na percepção dela, os meninos desafiavam mais os limites determinados por ela, entretanto as meninas eram mais "respondonas" e este comportamento delas incomodava mais a professora do que o comportamento desafiador deles. Um dos motivos para que isso acontecesse 
talvez fosse o fato de que eles estavam enquadrados no perfil que estamos acostumados/as a esperar dos/as meninos/as e as meninas, ao enfrentarem a professora, se afastavam do que se espera delas.

O professor Carlos definia as meninas como mais conversadeiras e as classificava como "gralhas". Os meninos, na opinião dele, eram mais compenetrados e tinham mais poder de concentração. A opinião das alunas desta turma divergia da visão do professor. Elas consideravam os meninos mais bagunceiros, porém reconheciam que o fato delas falarem mais alto dava a impressão de que elas eram as mais bagunceiras. Disse anteriormente que as meninas falavam mais baixo. Aparentemente estou me contradizendo porém a 7ạ série era diferenciada das demais turmas. Nesta turma as meninas eram mais ativas, participativas, falavam mais alto do que os meninos e, este fato que divergia do padrão do que é "ser menina", incomodava o professor.

Ao final do período de observação nesta turma tive dificuldade em selecionar os meninos e as meninas para a entrevista, pois sobrava meninas que se destacavam por diversos motivos e faltava meninos. Procurei contemplar dentre os/as entrevistados/as discentes participativos/as, medianos/as e calados/as pois acreditava que assim teriam uma amostra mais heterogênea. Acredito que consegui atingir este objetivo pois nas falas dos/as estudantes apareceram opiniões muito variadas, percepções distintas acerca do mesmo fato o que enriqueceu a pesquisa.

Tanto alunos/as quanto professores/as percebiam as meninas como mais organizadas, dedicadas, caprichosas do que os meninos. Eles por sua vez eram percebidos como irrequietos, ativos, participativos, desafiadores. Estas percepções evidenciavam que os estereótipos de gênero estavam presentes na visão do quadro docente e discente das turmas pesquisadas. Não haveria nenhum problema nisso se os adjetivos atribuídos aos meninos não fossem mais valorizados do que os atribuídos às meninas.

A vergonha e a necessidade de pertencimento ao grupo também foi notada durante a pesquisa. Raramente os/as estudantes esclareciam suas dúvidas durante as aulas. Isso foi percebido durante as observações e posteriormente confirmado por meio das entrevistas. Os/as estudantes afirmavam não perguntar devido ao receio de como os/as colegas iriam reagir. Se a colocação fosse acertada eles/as poderiam ser rotulados como nerd e se eles/as errassem poderiam ouvir um sonoro "eh burro". Os/as estudantes não queriam pertencer a nenhum destes grupos e por isso se calavam. Os/as professore/as compartilhavam da percepção dos/as estudantes e consideravam que este fato dificultava o aprendizado. É sabido que o conteúdo de Matemática é cumulativo e desta forma, não dirimir as dúvidas certamente dificulta a compreensão do conteúdo seguinte, ou seja, a vergonha e a reação dos/as colegas acaba interferindo diretamente no rendimento escolar de alunos e alunas. A reação dos/as colegas e dos/as professores/as silenciavam os/as estudantes e evitavam que eles e elas sanassem suas dúvidas e assim tivessem um melhor aprendizado.

Muitos/as estudantes percebiam que os comentários dos/as colegas podiam ser agressivos, causar dor e sofrimento. Muitas vezes estes comentários eram carregados de preconceito baseados em alguma característica vista como "diferente", "anormal", "fora do padrão". Cabe aqui alguns questionamentos. O que é ser diferente? E normal? Qual é o padrão? Existe um padrão? Na ideia 
dos/as estudantes e professores/as parece que existia um padrão do que é ser homem e ser mulher, menina ou menino e quem está fora deste "padrão" é visto como problemático e podem ser vítimas de preconceito.

A tentativa de se adequar a este padrão pode levar ao sofrimento pois estudantes que se afastam do mesmo se violentam para que sejam aceitos/as e vistos/as como normais, como pertencentes ao grupo. A necessidade de pertencimento ficou evidente na fala dos/as estudantes. Eles/as não queriam estar a margem das relações com os/as colegas. Queriam ser conhecidos e reconhecidos como um deles/as, como igual, como pertencente. Queriam se sentir inclusos/as e não ser marginalizados por uma suposta diferença que era, na maioria das vezes, vista como inferioridade. Cabe ressaltar que a diferença é bem vinda e desejada porém temos que evitar que esta diferença se traduza em desigualdade. A desigualdade leva a prejuízos de aprendizagem e de vida em sociedade.

Durante as observações pude perceber que as duas professoras tratavam meninos e meninas de forma diferenciada. Nos dois casos as professoras ouviam mais as solicitações dos meninos do que das meninas. Isto ficou evidente num dia de prova na 6a série quando a professora Marjorie, após ter atendido inúmeras vezes aos pedidos de ajuda e esclarecimento de dois meninos, ao ser questionada por uma menina disse em tom de irritação que não responderia mais nada a ninguém, não dirimindo a dúvida da aluna. Logo após, voltou a auxiliar os mesmos meninos evidenciando que a eles era permitido o pedido de ajuda e a elas não. As meninas se calaram, ou melhor, foram caladas.

$\mathrm{Na} 5^{a}$ série, o tratamento diferenciado por parte da professora ficou evidente no dia em que ela convidou os/as estudantes para se dirigirem à lousa para resolver os exercícios. Alguns meninos e uma menina (Stefanie) se prontificaram a ir e ela parecia não ouvir e nem ver a solicitação da menina. Depois de alguma insistência por parte da aluna, ela conseguiu ir ao quadro resolver uma questão. Como fiquei observando as aulas por 6 meses, pude perceber que Stefanie mudou completamente o comportamento naquele período. No início das observações ela era participativa e falante e no final estava silenciada. Não posso afirmar que isso se deu somente pelo comportamento da professora mas certamente o mesmo interferiu no silenciamento de Stefanie.

Convém salientar que a professora Marina que lecionava na 5a séria admitia a preferência por ensinar os meninos. Ela demonstrava um certo desconforto ao relatar este fato. Reconhecia que esta era uma dificuldade dela e que não havia nenhum indício de que os meninos eram melhores do que as meninas em Matemática, porém por um gosto pessoal ela reconhecia a preferência por eles.

No caso dos professores Carlos (7ạ série) e Rafael (8a série), não presenciei nenhum momento em que a preferência ou o privilégio por um dos sexos era evidente. Entretanto a aproximação entre os professores e os/as estudantes se dava em menor intensidade e de forma diferenciada. Os professores mantinham uma certa distância dos/as alunos/as e a interação era menos frequente entretanto mais profunda. Neste caso percebia-se que eles tinham preferência pelos/as estudantes que apresentavam melhor aprendizado. Eles afirmaram isso na entrevista. Também reconheciam que as meninas eram mais dedicadas, caprichosas e delicadas do que os meninos. Os meninos, na percepção dos professores, eram mais extrovertidos e desorganizados. Ou seja, tanto meninas 
quanto meninos eram percebidos de acordo do "padrão", do que era visto como normal para um menino e para uma menina. Os professores não percebiam nenhuma quebra de estereótipo, nenhum romper de barreiras.

Este comportamento diferenciado que levava meninas a perceberem os meninos como os que obtinham as melhores notas e os meninos a pensarem que elas é que obtinham melhores resultados não produzia diferença no rendimento escolar. Tanto meninas quanto meninos obtinham notas baixas nas avaliações realizadas pelos/as professores/as. Ou seja, o silenciamento produzido pelo receio do que os/as outros/as iriam pensar parece ter obtido melhor resultado do que o comportamento organizado e dedicado das meninas e do comportamento ativo e extrovertido dos meninos. O não dirimir as dúvidas parece afetar mais o rendimento escolar do que o comportamento visto como adequado para a aprendizagem que é a dedicação e o capricho. Ou seja, a vergonha e a necessidade de pertencimento assumem papel negativo no desenvolvimento escolar de meninas e meninos.

\section{CONSIDERAÇÕES FINAIS}

Durante a realização da pesquisa pude perceber que as interações entre os/as estudantes ocorrem de forma intensa porém, preferencialmente entre estudantes do mesmo sexo. Com este comportamento os/as estudantes desperdiçam a oportunidade de aprender com o/a outro/a. Deixam escapar a oportunidade de conhecimento que a interação pode proporcionar. Percebi que mesmo a educação sendo mista, turmas com meninas e meninos, parece que eles e elas vivem em mundos separados. Esta separação e distanciamento vai diminuindo de acordo com a faixa escolar dos/as estudantes. Na 5a série há uma separação quase total e na $8^{a}$ série já se percebe uma aproximação.

Convém salientar que a negação em interagir com os/as colegas do sexo oposto no ambiente escolar pode dificultar a relação entre homens e mulheres na vida em sociedade. Sabe-se que no dia a dia é impossível viver num mundo totalmente masculino ou totalmente feminino. Há a necessidade obrigatória de interação e a escola pode servir como um espaço para a aprendizagem e o treinamento deste convívio para que a relação seja a mais tranquila e equilibrada possível.

Percebi ainda que as relações de gênero passam praticamente despercebida pelos/as estudantes e pelos/as professores/as. Para a maioria parecia ser a primeira vez que foram convidados/as a refletir sobre a temática. Situações de preconceito ou de "supostas brincadeiras" que alguns/mas estudantes manifestavam em relação aos/às outros/as, e que muitas vezes eram baseadas na sexualidade, ou homossexualidade presumida, ou ainda no sexo, na cor/raça/etnia, na crença religiosa eram invisíveis para os/as professores/as. 0 despreparo para lidar com o fato fazia com que silenciassem.

O "dito" acerca das relações de gênero no cotidiano das aulas de matemática estava muito atrelado aos padrões e estereótipos do que é ser homem ou mulher. Tudo o que foge deste padrão ficava na categoria do "não dito" do silenciado. 


\title{
SAID AND NOT SAID ABOUT GENDER RELATIONS IN THE DAILY OF MATHEMATICS CLASS
}

\begin{abstract}
The purpose of this article is to present a portion of the results of the research for the accomplishment of the doctoral thesis whose objective was to analyze the gender relations in the quotidian of the mathematics classes from 5 th to 8 th grades of elementary school. The research was carried out in a college of the state education network of Curitiba, capital of the State of Paraná, Brazil. The research was based on the ethnographic method with observation, interview and document analysis. The analysis was made based on the theory of gender seeking to identify the said and not said about the gender relations present in that space. The results point to a silencing of gender relations and female students. They seem to have absorbed the idea that they should hear more than talk, that they should not expose themselves. They also point out the need for students to be recognized as belonging to the group. This need contributed to their silencing. Teachers and students perceived girls as passive and organized and boys as active and creative. In general, perceptions were based on stereotypes of what it is to be a man or a woman in today's society, a fact that shows that from a very early age these stereotypes are absorbed by girls and boys and become part of their ways of thinking and seeing relationships everyday life.
\end{abstract}

KEYWORDS: Gender Relations. Mathematics classes. Students. 
1 Trabalho Apresentado no X Congreso Iberoamericano de Género, Ciencia y Tecnologia realizado em 2014 em assunção - Paraguay.

2 A tese foi desenvolvida pela primeira autora sob a orientação da segunda. Quando eu estiver falando na primeira pessoa do singular estou me referindo a primeira autora.

3 Esta era a nomenclatura utilizada na época da pesquisa e equivale ao 6ㅇ ao 9o ano na atualidade.

4 Todos os nomes aqui apresentados são fictícios. O nome do colégio foi determinado por mim por se tratar de uma instituição com mais de 100 anos. Os/as demais entrevistados/as escolheram seus nomes fictícios.

5 Pássaro pequeno e barulhento.

\section{REFERÊNCIAS}

CASAGRANDE, Lindamir Salete. Entre silenciamentos e invisibilidades: as relações de gênero no cotidiano das aulas de matemática. 2011, 261f. Tese (Doutorado em Tecnologia), Programa de Pós-Graduação em Tecnologia, Universidade Tecnológica Federal do Paraná, Curitiba, 2011.

COSTA, Claudia de Lima. O leito do procusto. Cadernos Pagu, Campinas, p. 141174, 1994.

FELIPE, Jane; GUIZZO, Bianca Salazar. Erotização dos corpos infantis na sociedade de consumo. Pro-Posições, Campinas, v. 14, n. 3 (42), p. 121-130, set./dez. 2003.

SCOTT, Joan. Gênero: Uma categoria útil de análise histórica. Educação \& Realidade, Porto Alegre, v. 20, n. 2, p. 71-99, jul./dez. 1995.

SIMIÃO, Daniel Schroeter. Gênero no mundo do trabalho: variações sobre um tema. Cadernos de Gênero e Tecnologia, v. 5, ano 2, 2005, p. 9-20. 
Recebido: 20 de abril de 2016.

Aprovado: 19 de maio de 2016.

Como citar:

CASAGRANDE, Lindamir S.; CARVALHO, Marilia Gomes de. O dito e não dito acerca das relações de gênero no cotidiano das aulas de matemática. Cad. Gên. Tecnol., Curitiba, v. 9, n. 33, p. 5059, jan./jun. 2016.

Correspondência:

Lindamir Salete Casagrande

Rua Eurides Cunha, 85, apto. 1325. 80320010, Curitiba.

Direito autoral: Este artigo está licenciado sob os termos da Licença Creative Commons Atribuição 4.0 Internacional.

\section{(c) (i)}

